\title{
Occupational Injury Disparities in the US Hotel Industry*
}

\author{
Susan Buchanan, MD, MPH, ${ }^{1}$ * Pamela Vossenas, $\mathrm{MPH}^{2}{ }^{2}$ Niklas Krause, MD, $\mathrm{PhD}^{3}$ \\ Joan Moriarty, Ms, ${ }^{4}$ Eric Frumin, MA, ${ }^{4}$ Jo Anna M. Shimek, Ms, ${ }^{5}$ \\ Franklin Mirer, $\mathrm{PhD}, \mathrm{ClH}^{6}{ }^{6}$ Peter Orris, MD, MPH, ${ }^{7}$ and Laura Punnett, ScD ${ }^{8}$
}

\begin{abstract}
Background Hotel employees have higher rates of occupational injury and sustain more severe injuries than most other service workers.

Method OSHA log incidents from five unionized hotel companies for a three-year period were analyzed to estimate injury rates by job, company, and demographic characteristics. Room cleaning work, known to be physically hazardous, was of particular concern.

Results A total of 2,865 injuries were reported during 55,327 worker-years of observation. The overall injury rate was 5.2 injuries per 100 worker-years. The rate was highest for housekeepers (7.9), Hispanic housekeepers (10.6), and about double in three companies versus two others. Acute trauma rates were highest in kitchen workers (4.0/100) and housekeepers (3.9/100); housekeepers also had the highest rate of musculoskeletal disorders (3.2/100). Age, being female or Hispanic, job title, and company were all independently associated with injury risk.

Conclusion Sex-and ethnicity-based disparities in injury rates were only partially due to the type of job held and the company in which the work was performed. Am. J. Ind. Med. 53:116-125, 2010. () 2009 Wiley-Liss, Inc.
\end{abstract}

KEY WORDS: occupational injury; hotel workers; housekeepers; musculoskeletal disorders; health disparities

${ }^{1}$ Division of Environmental and Occupational Health Sciences, University of Illinois at Chicago School of Public Health, Chicago, Illinois

${ }^{2}$ Occupational Safety and Health Program, UNITE HERE, New York, New York

${ }^{3}$ Division of Occupational and Environmental Medicine, University of California San Francisco, San Franciso, California

${ }^{4}$ Workers United/SEIU, New York, New York

${ }^{5}$ Division of Environmental and Occupational Health Sciences, University of Illinois at Chicago School of Public Health, Chicago, Illinois

${ }^{6}$ Environmental and Occupational Health Sciences, Urban Public Health Program, Hunter College School of Health Sciences, New York, New York

${ }^{7}$ Department of Occupational and Environmental Medicine, University of Illinois at Chicago Medical Center, Chicago, Illinois

${ }^{8}$ Department of Work Environment, University of Massachusetts Lowell, Lowell, Massachusetts

*Work conducted while Joan Moriarty and Eric Frumin were at UNITE HERE.

Contract grant sponsor:UNITE HERE.

*Correspondenceto:Susan Buchanan,MD,MPH,835S.Wolcott,MC-684,Chicago,IL60612. E-mail: sbucha3@uic.edu

Accepted 22 May 2009

DOl 10.1002/ajim.20724. Published online in Wiley InterScience

(www.interscience.wiley.com)

\section{BACKGROUND}

Health disparities between the sexes and between racial/ ethnic groups have been documented for a wide spectrum of diseases [Satcher and Higginbotham, 2008] but research on disparities in the rates of injuries and diseases occurring in the workplace is still emerging. Recent studies have shown that Hispanic workers have the highest rate of fatal and non-fatal OSHA-reported injuries in the US, followed by black nonHispanic workers [Richardson et al., 2003; USBLS, 2007a]. Among agricultural and hospital workers, a disproportionate burden of occupational injury is carried by women, African Americans, and Latinos [McGwin et al., 2000; Simpson and Severson, 2000; McCurdy et al., 2003]. Elevated risks among these groups are partially explained by disproportionate employment in high-risk industries and occupations, but there may also be disparities within the same industry or job classification, perhaps resulting from sex, racial, or ethnic discrimination and other factors. 
Within the US hospitality industry, hotels, and motels employ 1.8 million workers [USBLS, 2007b]. In the United States, hotel workers are nearly $40 \%$ more likely to be injured on the job than all other service sector workers. Hotel workers also sustain more severe injuries resulting in more days off work, more job transfers, and more medically restricted work compared to other employees in the hospitality industry [USBLS, 2005].

Approximately $25 \%$ of hotel workers are employed in housekeeping departments [USBLS, 2007b]. Housekeepers constitute the single largest occupational group in the hotel industry and include room cleaners (maids or room attendants) and housemen. Many room attendants are immigrant or minority women, with a majority being either Asian, Latin American, or African American [Wial and Rickert, 2002]. Thus, they belong to several groups that have been repeatedly identified as having excessive occupational risks: women [Stellman, 1999; NIOSH, 2002; Kauppinen et al., 2003; Messing, 2004; Treaster and Burr, 2004], immigrants [Improving Health and Safety Conditions for California's Immigrant Workers, 2002], ethnic/racial minorities [Frumkin et al., 1999], and low-wage workers [Frumkin and Pransky, 1999]. However, very little is known about occupational injuries among hotel housekeepers; the US Bureau of Labor Statistics (BLS) does not provide rates of occupational injury and illness for single occupations. Among Las Vegas hotel room cleaners, the prevalence of self-reported pain associated with work was $75 \%$ during the previous year [Scherzer et al., 2005]; 63\% had had severe or very severe low back pain just in the prior month [Krause et al., 2005].

In 1996, the first National Institute for Occupational Safety and Health (NIOSH) research agenda ("NORA") called for innovative occupational health research to determine the extent and severity of disease and injury among special worker populations [NIOSH, 1996]. Ten years later, the revised NORA research agenda targeted the service sector, which accounts for $80 \%$ of the US workforce. Hotel workers have been repeatedly identified as an under -researched population with significant problems such as musculoskeletal injuries; even less is known about dishwashers, cooks, and other food service workers.

This study analyzes the rates of OSHA-reported injury within the hotel industry for four leading hotel job categories (hotel housekeepers, cooks/kitchen workers, stewards/ dishwashers, and banquet servers), and examines disparities in injury risk by race/ethnicity and sex.

\section{METHODS}

\section{Study Population}

Institutional Review Board approval was obtained from the University of Illinois at Chicago under the "exempt" classification. The study population consisted of non- supervisory hotel workers employed for a minimum of 2 weeks in at least 1 year during the study period of 2003-2005, at full-service hotels operated by the five largest hotel companies in the United States. For this study, full-service hotels are defined as properties with at least 100 guest rooms and with a minimum of 10,000 square feet of conference space. These criteria were intended to increase the likelihood that job classifications and workplace exposures to ergonomic and safety hazards would be similar. Luxury chains were excluded because the design and pace of work varies significantly at these properties.

The five companies operate several hotel chains that together make up over $70 \%$ of the full-service hotel rooms nationwide, with each company establishing its own standards of service. According to information found on the companies' public websites in February 2007, these companies operate 964 hotel properties in the US that meet the study's definition of full-service hotels. UNITE HERE, the largest hospitality workers union in North America, represents workers at many of these hotels.

\section{Hotel Sampling}

Upon request from the union, 71 of the hotels with collectively bargained contracts provided data, which could be utilized for this study. The two largest companies represented an unbalanced proportion of the sample, so a random number generator [Research Randomizer, 1997-2008] was used to select 12 hotels from each of these two. All hotels from the three other companies were included in the data analysis. This produced a sample of 50 hotels with sufficient data from 2003 to 2004 and 45 from 2005 (Table I). Study hotels were dispersed across the country with concentrations in large urban areas including New York City, Chicago, San Francisco, Los Angeles, and Honolulu.

\section{Job Classifications}

Job titles are numerous within hotel departments and vary from employer to employer. The authors in collaboration with

TABLE I. HotelCompany Distributions of USFull-Service Hotels and Hotels in the Study Sample

\begin{tabular}{|c|c|c|c|c|}
\hline \multirow[b]{2}{*}{ Company } & \multicolumn{2}{|c|}{ Full-service hotels } & \multicolumn{2}{|c|}{ Study sample } \\
\hline & No. & $\%$ & No. & $\%$ \\
\hline Company 1 & 334 & 35 & 12 & 24 \\
\hline Company 2 & 95 & 10 & 12 & 24 \\
\hline Company 3 & 10 & 1 & 5 & 10 \\
\hline Company 4 & 319 & 33 & 9 & 18 \\
\hline Company 5 & 206 & 21 & 12 & 24 \\
\hline Totals & 964 & 100 & 50 & 100 \\
\hline
\end{tabular}


experienced union field staff familiar with the specific job titles, grouped the jobs that share similar tasks and exposures to workplace hazards (e.g., "dishwasher" and "pot washer," "housekeeping attendant" and "room attendant"). Five key job categories were created-housekeepers, banquet servers, stewards/dishwashers, cooks/kitchen workers, and "other." Housekeepers perform guest room cleaning including making beds, vacuuming floors, cleaning shower walls and bathroom fixtures, dusting furniture, and pushing carts. Banquet servers provide food service such as carrying plated food from the kitchens to the customers, dispensing drinks, and supplying food to cafeteria and buffet services. Stewards retrieve, sort, load/lift, unload, and return dishes, glasses, pots, utensils and silverware, and provide these items by pushing carts to cafeteria and buffet lines. In addition, stewards maintain cleanliness in food preparation areas. Cooks lift, weigh, measure, mix, cut and grind food ingredients; they cook these ingredients and compose salads and other food for serving [USBLS Occupational Outlook Handbook, 2008-2009]. All remaining jobs were categorized as "other." Jobs classified as "other" were those that did not share similar job tasks or exposures with the other four key job categories. These included lobby attendant, cashier, door person, host/hostess, among others.

\section{Database Creation}

Employee rosters and OSHA $300 \log$ data were provided to the union by the five hotel companies for the period 2003-2005. The employee rosters provided employee name, department, job title, date of birth, date of hire, termination date, sex, and race/ethnicity. Race/ethnicity was defined by the employer based on employee self-report as one of the following five mutually exclusive categories: American Indian, Asian, Black, Hispanic, and White.

The OSHA 300 logs included employee name, department name or location where injury event occurred, job title, date of injury, injury description, days away from work, and days on restricted duty. These data were matched to the employee rosters using employee name and date of birth. The final dataset included a single record for each employee. Up to three injury or illness incidents during the 3-year study period were abstracted for each individual. Employee names were removed from all datasets before data analysis began. A record number was assigned to each injury incident and was subsequently used in all data analyses.

\section{Injury Coding}

Nature of injury data was constructed from the injury description section of OSHA log entries and were grouped by the authors into four categories: musculoskeletal disorders (MSDs), acute trauma injuries, other, and not classifiable. MSDs were coded according to the US BLS definition: "an injury or disorder of the muscles, nerves, tendons, joints, cartilage, or spinal discs. MSDs do not include disorders caused by slips, trips, falls, motor vehicle accidents, or similar accidents" [USBLS, 2007c]. Back pain or pain at other body locations and strain or sprain injuries were coded as MSDs unless the entry referenced stairs or ladders, or the employer-reported description of the injury referenced a slip or fall. "Acute trauma" cases included contusions, fractures, lacerations, heat burns, and sprain or strain injuries with evidence of an injury mechanism that involves acute contact with outside objects (e.g., hit by, struck against) that were not otherwise categorized as an MSD. "Other" incidents included chemical exposures, foreign bodies in the eye, and all other cases. "Not classifiable" injuries had insufficient information to determine the nature of injury.

\section{Statistical Analysis}

All data were analyzed using SAS (SAS v. 9.1, 2007. SAS Institute, Cary, NC) and Excel (Microsoft Office 2003, Seattle, Washington). Injury rates and risk ratios were calculated to compare the injury experience of hotel workers by sex, race/ethnicity, and job title for the entire study population and by company. The denominator for all calculations was calculated from the number of workers who met the inclusion criterion of employment for a minimum of 2 weeks during each year of study. As individual employees may be counted in more than one study year, the denominators represent total worker-years of observation. The available data did not provide information on part-time/full-time status. The race and ethnicity characterization was left blank on the employee rosters for $<1 \%$ of the sample. Therefore, this race/ethnicity "not classified" group was excluded from all data analyses.

Age was computed by subtracting birth date from the last day of the year being analyzed (e.g., in 2003, Age $=12 / 31$ / 2003 - birth date) divided by 365.25 . Only employees aged 18-70 years were included in the analysis. A job tenure variable was similarly created by subtracting termination date from hiring date.

Risk ratios were calculated using the following referent groups: males, whites, and "other" job title. For analyses by hotel company, Company 1 was chosen as the referent group on the basis of the level of union presence at its hotels, thereby a measure of labor and management's negotiation of working conditions.

Because we had injury count data and repeated measures (multiple years per subject), we performed multivariable Poisson regression modeling (Loomis et al. 2005) with generalized estimating equations (GEE) using SAS Proc Genmod with a Poisson distribution, unstructured correlations and $\log$ link to estimate relative risk. Regression models included age (18-27 years, $28-37$ years, $48-57$ years, 58-70 years), sex, race/ethnicity, job title, job tenure (0-10 
TABLE II. Demographic Breakdown of Hotel Workers ${ }^{\star}$ Employed 2003-2005 in 50 Unionized Full-Service Hotels $(n=55,327)$

\begin{tabular}{|c|c|c|c|c|c|c|c|c|c|c|c|c|}
\hline & \multicolumn{2}{|c|}{ Total } & \multicolumn{2}{|c|}{ Housekeeper } & \multicolumn{2}{|c|}{ Banquet server } & \multicolumn{2}{|c|}{ Steward/dishwasher } & \multicolumn{2}{|c|}{ Cook/kitchen worker } & \multicolumn{2}{|c|}{ Other jobs } \\
\hline & No. & $\%$ & No. & $\%$ & No. & $\%$ & No. & $\%$ & No. & $\%$ & No. & $\%$ \\
\hline Male & 31,135 & 56.4 & 269 & 2.3 & 3,406 & 66.8 & 2,948 & 85.1 & 3,269 & 72.0 & 20,280 & 69.2 \\
\hline Female & 24,048 & 43.6 & 11,320 & 97.7 & 1,693 & 33.2 & 518 & 14.9 & 1,271 & 28.0 & 9,008 & 30.8 \\
\hline White & 11,187 & 20.3 & 982 & 8.4 & 2,137 & 36.8 & 286 & 8.1 & 882 & 19.3 & 6,898 & 23.3 \\
\hline Asian & 13,352 & 24.2 & 3,109 & 26.7 & 909 & 15.6 & 594 & 16.9 & 1,202 & 26.3 & 7,538 & 25.4 \\
\hline Black & 12,252 & 22.2 & 3,439 & 29.5 & 712 & 12.3 & 962 & 27.3 & 872 & 19.0 & 6,267 & 21.1 \\
\hline Hispanic & 18,392 & 33.3 & 4,118 & 35.3 & 2,047 & 35.3 & 1,678 & 47.7 & 1,622 & 35.4 & 8,927 & 30.1 \\
\hline $\begin{array}{l}\text { American } \\
\text { Indian }\end{array}$ & 144 & $<1$ & 12 & $<1$ & 32 & $<1$ & 7 & $<1$ & 10 & $<1$ & 83 & $<1$ \\
\hline Total (\%) & 55,327 & 100.0 & 11,660 & 21.1 & 5,837 & 10.5 & 3,527 & 6.4 & 4,588 & 8.3 & 29,713 & 53.7 \\
\hline
\end{tabular}

${ }^{*}$ Total person-years observed, not total employees.

atotal excludes race "not specified" ( $<1 \%$ of total).

years, $11-20$ years, $21-30$ years, $31-40$ years, $41-52$ years), and hotel company as independent variables. In addition, cross tabulation and regression modeling were performed within the subset of female housekeepers. Similar analyses were not conducted within other subsets of other job classifications; female housekeepers were a particularly large subset.

\section{RESULTS}

There were a total of 55,327 worker-years of observation in the sample. Fifty-six percent of the sample was male and $44 \%$ female (Table II). By job title, $21 \%$ of the employees were housekeepers, $11 \%$ were banquet servers, $6 \%$ were stewards/dishwashers, $8 \%$ were cooks/kitchen workers, and $54 \%$ had other jobs. Most of the workers were non-white (Black, Asian, Hispanic), comprising $80 \%$ of the sample. American Indians and male housekeepers were very few in number. Hispanics comprised the largest proportion of three job titles: housekeepers, stewards, and cooks. The mean age of the study population was 44.5 years (SD 13.5). The mean job tenure was 9.61 years (SD 8.8).

There were 2,865 injuries recorded on the OSHA $300 \operatorname{logs}$ in 2003-2005 (Table III), for an injury rate of 5.2 injuries per 100 worker-years. Acute trauma accounted for $52 \%$ of the injuries, $39 \%$ were musculoskeletal injuries, and $9 \%$ were "other" or "not classifiable." Women workers had a higher overall injury rate (6.3) than men (4.3).

Housekeepers had the highest overall injury rate and the highest rate of MSDs, at 7.9 and 3.2 per 100 workers, respectively. Acute trauma rates were highest in cooks/ kitchen workers and housekeepers. Banquet servers had the lowest injury rates. Excluding the six injuries among American Indians, among housekeepers (Table IV), Hispanic workers had the highest overall injury rate at 10.6, the highest rate of MSDs (4.4), and the highest rate of acute traumas
(4.9). Among cooks (not shown), Asians had the highest rate: $8.4 \%$ for all injuries, with $7.9 \%$ among males and $10.1 \%$ among females.

In each job title of interest (housekeepers, etc.), injuries of the upper extremity were the most common, followed by back injuries and lower extremity injuries. By nature of injury, over $40 \%$ of MSDs involved the back, $22 \%$ distal upper extremities, and $13 \%$ the shoulder. In contrast, $44 \%$ of acute traumatic incidents were to the upper extremity, especially the hand.

Women workers overall and Asian and Hispanic men were about 1.5 times more likely to have been injured than their referent groups (Table V). Female American Indians fared the worst, although the number of injuries were so few that the confidence intervals are relatively wide. Hispanic women had almost double the risk of injury than their white female counterparts. Within job categories, non-white female cooks/kitchen workers fared poorly compared to their white counterparts as did non-white male banquet servers. Female housekeepers had about three times the risk of injury than male housekeepers, and Hispanic housekeepers were $70 \%$ more likely to be injured than white female housekeepers.

When analyzed by hotel company, the overall injury rates differed markedly by company, with companies 2,3 , and 4 in particular having almost twice the rate of Company 1 (Table VI). Company 2 had the highest rate of injury for housekeepers (10.4). This overall effect was consistent in analysis by injury type, with the lowest rates for both MSDs and acute trauma injuries in Company 1 . These same patterns by company were also evident for key demographic groups within the four key jobs. Of the 15 job/race/sex groups with sufficient cases for comparison, Companies 2 and 3 had the highest injury rates for five of them and Company 4 had almost as many. Company 1 had only one such group, and Company 5 had none. 


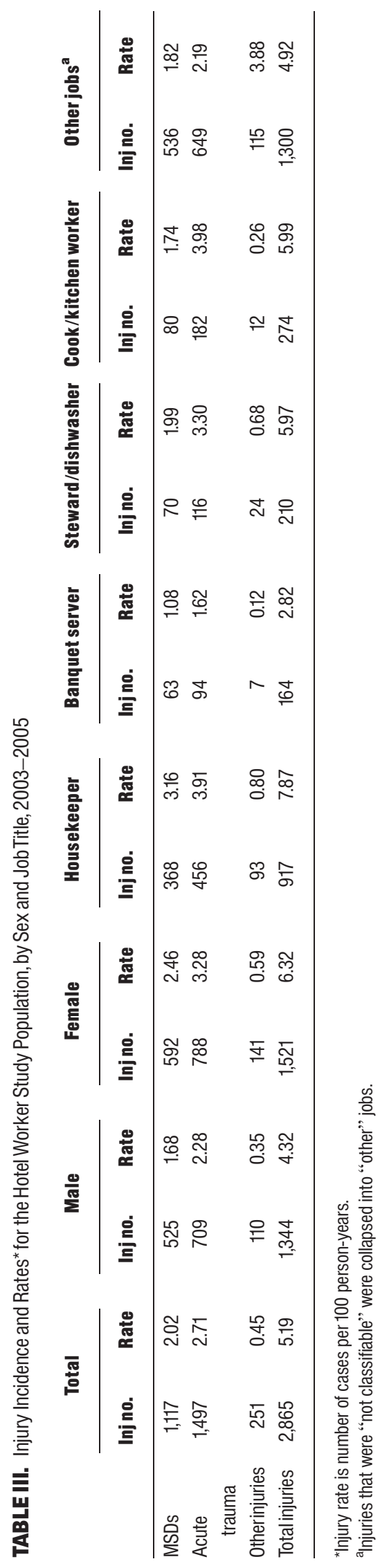

The regression analyses of all hotel workers (Table VII) confirmed the higher injury risk for housekeepers and Hispanic workers, and the lower risk in Company 1, after adjusting for demographic characteristics. Comparison of univariable and multivariable models showed that some of the apparent excess risk in Black, Hispanic, and Asian workers was reduced after adjustment for job title and hotel company. This was consistent with the fact that Blacks were most likely (30\%), and Whites least likely (8\%), to be employed as housekeepers rather than in other jobs, and that Company 1 had fewer Black and Asian employees. Job tenure had a slight inverted-U effect (risk was highest for 21-30 years of seniority and then decreased) but it was dropped from the multivariable models because the coefficient was very small, the confidence intervals wide, and the type 3 (GEE) score statistics indicated that the variable did not contribute any explanatory power. Among female housekeepers, the predictors of injury were quite similar to those for all hotel workers, with increased risk for being Hispanic or employment at Companies 2, 3, and 4.

\section{DISCUSSION}

Several studies have shown that cleaning tasks in various industries demand a high level of physical effort, including high aerobic strain and repetitive movements [Hagner and Hagberg, 1989]; high static muscular loads [Milburn and Barrett, 1999]; high frequency of unsatisfactory postures such as stooping and crouching [Woods et al., 1999]; and subjective experience of strenuous work [Sogaard et al., 1996; Seifert and Messing, 2006]. In hotel workers specifically, guest room cleaning work is marked by time pressure, low job control, low wages, increasing use of contingent employees without job security, and few opportunities for career advancement [Parker, 1999; Lee and Krause, 2002; Wial and Rickert, 2002; Bernhardt et al., 2003; Krause et al., 2005]. The present study is one of the first to quantify the incidence, rates, and risk of injury among hotel workers.

We found that women were more often injured than men and that housekeepers in general suffered the highest injury rate among the four job titles of interest. Moreover, our results show an alarming injury rate among housekeepers in general and Hispanic housekeepers in particular. While close to half of the total workers here are women, they were heavily grouped in the housekeeping category, a set of jobs with very high physical demands. This study strengthens the evidence that job gender stereotyping within the American economy remains a potent defining factor for the workforce and potentially a substantial risk factor for injury [Mergler, 1995; Messing et al., 1998, 2003; Punnett and Herbert, 2000].

Socioeconomic status (SES) in general, and income inequality, education, and job-specific occupational hazards in particular, have all been proposed as possible explanations for racial/ethnic as well as gender health disparities. There is 
TABLE IV. Injury Incidence and Rates* for Housekeepers by Race/Ethnicity, 2003-2005

\begin{tabular}{|c|c|c|c|c|c|c|c|c|}
\hline & \multicolumn{2}{|c|}{ All injuries } & \multicolumn{2}{|c|}{ MSDs } & \multicolumn{2}{|c|}{ Acute trauma } & \multicolumn{2}{|c|}{ Other/not classifiable } \\
\hline & Inj no. & Rate & Inj no. & Rate & Inj no. & Rate & Inj no. & Rate \\
\hline Asian & 228 & 7.33 & 102 & 3.28 & 106 & 3.41 & 20 & 0.64 \\
\hline Black & 189 & 5.50 & 58 & 1.69 & 113 & 3.29 & 18 & 0.52 \\
\hline Hispanic & 435 & 10.56 & 183 & 4.44 & 203 & 4.93 & 49 & 1.19 \\
\hline White & 62 & 6.31 & 24 & 2.44 & 32 & 3.26 & 6 & 0.61 \\
\hline American Indian & 6 & 50.00 & 1 & 8.33 & 5 & 41.67 & None & \\
\hline Total $^{\mathrm{a}}$ & 920 & 7.89 & 368 & 3.16 & 459 & 3.94 & 93 & 0.80 \\
\hline
\end{tabular}

*Injury rate is number of cases per 100 person-years.

aTotal excludes race "not specified" ( $<1 \%$ of total).

consistent epidemiologic evidence that low status jobs are associated with a high burden of disease, injury, and disability [Robinson, 1989; Krause et al., 1997, 2001; Amick et al., 1998; Borg and Kristensen, 2000; Pransky et al., 2000; Berkman and Kawachi, 2002; d'Errico et al., 2007]. This burden falls disproportionately on workers who are multiply disadvantaged in society and who have been under-represented and under-served in occupational health research. Female immigrant cleaners are a typical example of a minority population at the low end of the well-established SES gradient.

As yet, there has been no evaluation of the causes of differential injury rates by race/ethnicity within job title in this industry. One must question whether discrimination in the treatment of such workers-in the form of disproportionate assignment to high-risk jobs, refusal to fix unsafe conditions, or workers' disempowerment-resulting in unwillingness to speak up about such conditions, is at fault. As Murray [2003] noted, previous studies have observed informal systems of work assignments to non-white workers resulting in greater exposures to the hazards therein. Moreover, US BLS has already found that disproportionate employment of Hispanics in specific jobs is not associated with increased risk of injury after controlling for such employment patterns [Richardson et al., 2003]. In essence, race/ ethnicity itself is not an indicator of increased risk.

The injury rate for the workers in this sample was 5.19 per 100 workers. For 2004, the US BLS reported a rate of 5.8 per 100 FTEs in hotel workers and 4.2 per 100 FTEs in the service sector overall. The lower overall injury rate reported in our sample may be due to the inability to identify the proportion of part time workers in this sample or that unionized employees work under conditions defined by collective bargaining agreements, which are intended to improve workplace safety. The study sample included only unionized workers, whereas the majority of US hotel employees do not belong to unions. Since unions function as the bargaining agent between the employer and the employee, it is likely that non-unionized hotels, in which workers do not have a formal means to gain better working conditions, would have even higher injury rates than those reported in this study. Further, it is possible that hotels not providing data were those at which workplace safety is less of a priority and which have higher injury rates than those reported here.

These results also need to be seen in the context of the tendency of many workers not to report their injuries, especially if they are non-unionized, immigrants, or otherwise politically vulnerable [Azaroff et al., 2002, 2004; Brown et al., 2002; Scherzer et al., 2005]. Non-reporting of injuries may be due to language barriers, fear of retaliation, or lack of understanding of legal rights under Workers Compensation laws and OSHA standards. Although our data represent unionized workers who reported their injuries, the results may still represent an under-estimation of the true injury risk.

Other possible limitations to this study include quality of the data, coding, and job grouping errors. Injury data obtained from OSHA 300 logs may have contained inaccuracies. The individual responsible for completing these logs varies by workplace and is not always well trained in correct recording procedures. There may well be systematic differential approaches to OSHA $300 \log$ completion by different hotel companies. Nevertheless, we saw no evidence of frequent recording errors or systemic bias in recording through regular quality control checks as well as consultations with experts on the coding and grouping criteria. Although the high rate of acute injuries in housekeepers may suggest coding errors, the OSHA logs frequently included event/exposure data such as contact with furniture, tripping over sheets, slips in bathtubs, etc. Furthermore, coding error is possible since some acute injuries in housekeeping may have been MSDs. However, the patterns of injury we found are also seen in US BLS data.

The hotels in this study sample were included based on number of rooms and size of meeting space in order to ensure similarity in job task burden among workers in the sample. Working conditions in full-service hotels are determined and standardized in major part by corporate-level policies such as 

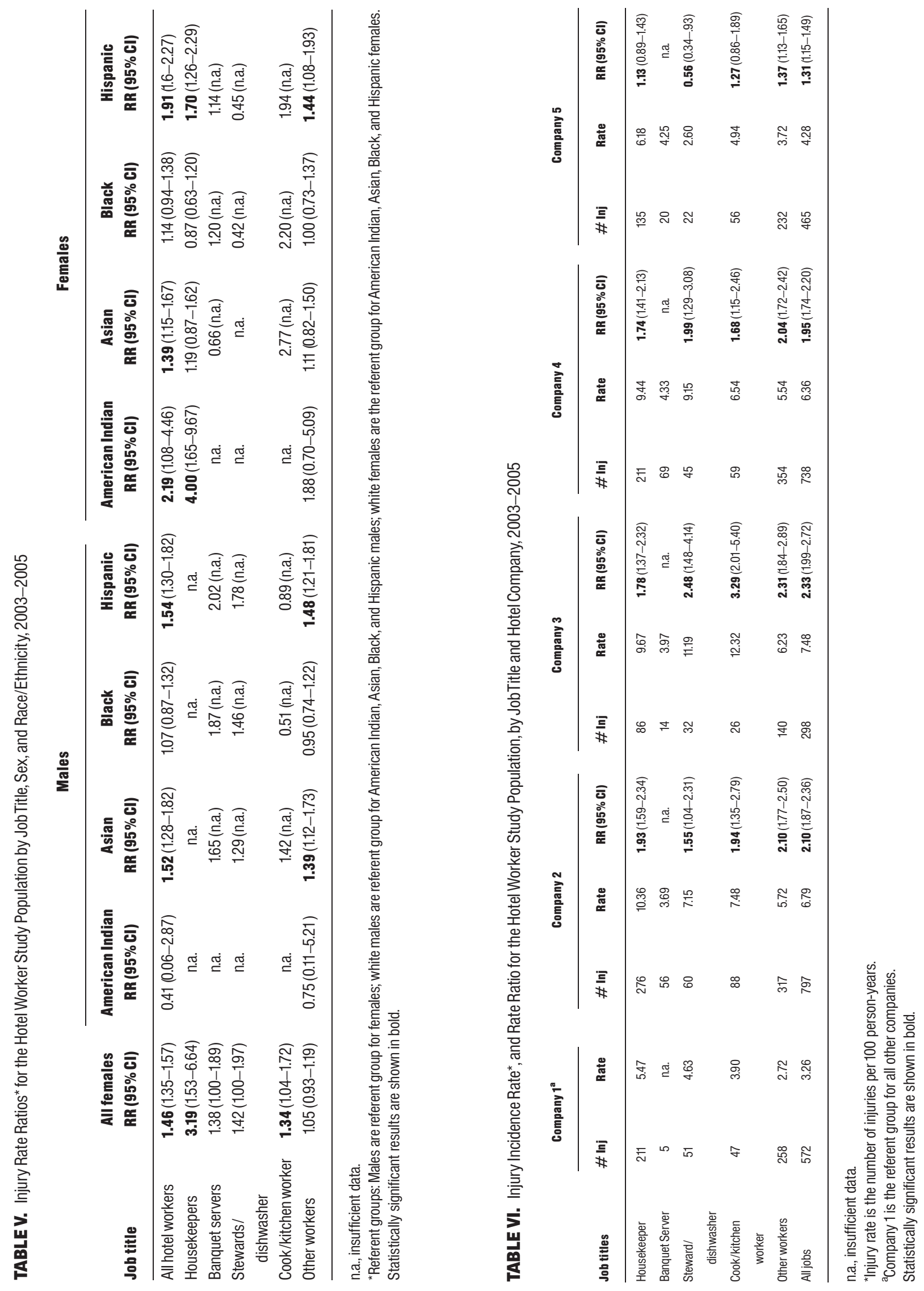
TABLE VII. Regression Models of Injuries Per Year^ to US Unionized Hotel workers, 2003-2005: Risk Ratios and 95\% Confidence Intervals

\begin{tabular}{|c|c|c|c|c|c|c|c|c|}
\hline & \multicolumn{2}{|c|}{$\begin{array}{c}\text { Unadjusted models } \\
\text { (all hotel workers) }\end{array}$} & \multicolumn{2}{|c|}{$\begin{array}{l}\text { Multivariable model } \\
\text { (all hotel workers) }\end{array}$} & \multicolumn{2}{|c|}{$\begin{array}{l}\text { Multivariable model } \\
\text { (all hotel workers) }\end{array}$} & \multicolumn{2}{|c|}{$\begin{array}{l}\text { Multivariable model } \\
\text { (female housekeepers) }\end{array}$} \\
\hline & Odds ratio & $95 \% \mathrm{Cl}$ & Odds ratio & $95 \% \mathrm{Cl}$ & Odds ratio & $95 \% \mathrm{Cl}$ & Odds ratio & $95 \% \mathrm{CI}$ \\
\hline Age & 1.07 & $1.04-1.09$ & 1.08 & $1.05-1.11$ & 1.09 & $1.06-1.12$ & 1.10 & $1.03-1.18$ \\
\hline Job tenure & 1.08 & $1.04-1.12$ & & & & & & \\
\hline Female & 1.46 & $1.35-1.58$ & 1.24 & $1.12-1.37$ & 1.21 & $1.09-1.34$ & & \\
\hline American Indian & 1.35 & $0.67-2.72$ & 1.33 & $0.68-2.61$ & 1.15 & $0.60-2.22$ & 2.54 & $1.05-6.13$ \\
\hline Asian & 1.46 & $1.29-1.67$ & 1.25 & $1.10-1.42$ & 1.11 & $0.97-1.26$ & 0.97 & $0.71-1.33$ \\
\hline Black & 1.15 & $1.00-1.32$ & 0.97 & $0.84-1.11$ & 0.85 & $0.74-0.98$ & 0.75 & $0.54-1.03$ \\
\hline Hispanic & 1.70 & $1.50-1.92$ & 1.50 & $1.33-1.70$ & 1.42 & $1.26-1.61$ & 1.50 & $1.11-2.02$ \\
\hline Housekeeper & 1.80 & $1.65-1.97$ & 1.50 & $1.34-1.68$ & 1.52 & $1.36-1.70$ & & \\
\hline Banquet server & 0.64 & $0.54-0.77$ & 0.60 & $0.50-0.72$ & 0.56 & $0.47-0.67$ & & \\
\hline $\begin{array}{l}\text { Steward/ } \\
\text { dishwasher }\end{array}$ & 1.37 & $1.17-1.61$ & 1.30 & $1.11-1.53$ & 1.31 & $1.12-1.54$ & & \\
\hline $\begin{array}{l}\text { Cook/kitchen } \\
\text { worker }\end{array}$ & 1.38 & $1.20-1.58$ & 1.34 & $1.17-1.54$ & 1.31 & $1.15-1.51$ & & \\
\hline Company 2 & 2.10 & $1.87-2.36$ & & & 2.17 & $1.94-2.44$ & 1.94 & $1.59-2.35$ \\
\hline Company 3 & 2.33 & $1.99-2.72$ & & & 2.41 & $2.07-2.81$ & 1.84 & $1.41-2.39$ \\
\hline Company 4 & 1.95 & $1.74-2.20$ & & & 2.06 & $1.83-2.32$ & 1.74 & $1.41-2.14$ \\
\hline Company 5 & 1.31 & $1.15-1.50$ & & & 1.37 & $1.20-1.56$ & 1.19 & $0.94-1.50$ \\
\hline
\end{tabular}

Male is the referent group for female; White is the referent group for Black, Hispanic, Asian, and American Indian; " OOther jobs” is the referent group for housekeeper, banquet server, steward, and cook/kitchen worker; Company 1 is the referent group.

*Up to three injuries per year per employee; denominators $=55,311$ person-years of observation for all hotel workers and 11,375 person-years for female housekeepers.

job task lists and the use of branded products such as luxury beds. Hotels with fewer than 100 rooms would be less likely to have standardized room quotas, which might affect workload pressure and therefore injury risk among housekeepers. Thus, we believe that the inter- and intra-hotel variations in work tasks among job title groups are likely to be minimal in our sample of properties.

There were substantial and consistent differences in injury rates among the five companies. These differences persisted for all injuries, for injuries by job title, and by demographic groups. As this study sought to standardize job tasks between companies, this differential suggests the influence of management policies and practices, meaning that workplace intervention has a significant ability to modify the risks identified in this study. These marked differences between companies demonstrate the potential for sharp improvement by individual companies in injury rates. They also underscore the need for companies with high rates to investigate whether discriminatory workplace practices contribute to these disparities-in order to remedy the discrimination and reduce the injury risk accordingly.

\section{CONCLUSION}

Injury rates for hotel workers are higher than those in the service sector as a whole. Characteristics that increased the injury risk among the workers in our study included female sex, Hispanic ethnicity, housekeeper job title, and hotel company. Hispanic banquet servers had the highest risk amongst men, and American Indian housekeepers had the highest risk among women. Hispanic female housekeepers suffered more injuries than other female room cleaners. Immediate action is needed with respect to the control of hazards to housekeepers, especially those stressing the upper extremities, and to food service workers with respect to acute trauma. The ethnic, gender, and employer differentials deserve further exploration to adequately understand the interaction of social forces with ergonomic and safety hazards in the workplace. Large differences of injury rates between employers indicate a substantial potential for injury prevention in the hotel sector.

\section{ACKNOWLEDGMENTS}

Financial support for the data analysis was provided by UNITE HERE. The following individuals contributed to this study: Christopher E. Mason, PhD, employee hiring list data preparation; Emily Perry, BA, research on full service hotel sector; and John M. Halpin, MD, MPH, housekeeper injury analysis of earlier version of dataset. We are grateful to Rebecca Gore, $\mathrm{PhD}$ for statistical advice. 


\section{REFERENCES}

Amick BC III, Kawachi I, Coakley EH, Lerner D, Levine S, Colditz GA. 1998. Relationship of job strain and iso-strain to health status in a cohort of women in the United States. Scand J Work Environ Health 24(1): $54-61$.

Azaroff L, Levenstein C, Wegman DH. 2002. Occupational injury and illness surveillance: Conceptual filters explain underreporting. Am J Public Health 92:1421-1429.

Azaroff LS, Lax MB, Levenstein C, Wegman DH. 2004. Wounding the messenger: The new economy makes occupational health indicators too good to be true. Int J Health Serv 2004. 34:271303.

Berkman SF, Kawachi I. editors. 2002. Social epidemiology. New York: Oxford University Press.

Bernhardt A, Dresser L, Hatton E. 2003. The coffee pot wars: Unions and firm restructuring in the hotel industry. In: Appelbaum E, Bernhardt A, Murnane RJ, editors. Low-wage America: How employers are reshaping opportunity in the workplace. New York: Russell Sage Foundation, p 33-76.

Borg V, Kristensen TS. 2000. Social class and self-rated health: Can the gradient be explained by differences in life style or work environment? Soc Sci Med 51(7):1019-1030.

Brown MP, Domenzain A, Villoria-Siegert N. 2002. California's immigrant workers speak up about health and safety in the workplace. Los Angeles, California: University of California Los Angeles Labor Occupational Safety and Health Program Health and Safety Policy Brief.

d'Errico A, Punnett L, Cifuentes M, Boyer J, Tessler J, Gore R, Scollin P, Slatin C. 2007. Hospital injury rates in relation to socioeconomic status and working conditions. Occup Environ Med 64(5):325-333.

Frumkin H, Pransky G. 1999. Special populations in occupational health. Occup Med 14(3):479-484.

Frumkin H, Walker ED, Friedman-Jimenez G. 1999. Minority workers and communities. Occup Med 14(3):495-517.

Hagner IM, Hagberg M. 1989. Evaluation of two floor-mopping work methods by measurement of load. Ergonomics 32(4):401-408.

Improving Health and Safety Conditions for California's Immigrant Workers. Report and Recommendations of the California Working Immigrant Safety and Health Coalition. November 2002. Berkeley, California.

Kauppinen K, Kumpulainen R, Copsey S. 2003. Gender issues in safety and health at work-A review. Finland: European Agency for Safety and Health at Work.

Krause N, Lynch J, Kaplan GA, Cohen RD, Goldberg DE, Salonen JT. 1997. Predictors of disability retirement. Scand J Work Environ Health 23:403-413.

Krause N, Frank JW, Dasinger LK, Sullivan TJ, Sinclair SJ. 2001. Determinants of duration of disability and return-to-work after workrelated injury and illness: Challenges for future research. Am J Ind Med 40(4):464-484.

Krause N, Scherzer T, Rugulies R. 2005. Physical workload, work intensification, and prevalence of pain in low wage workers: Results from a participatory research project with hotel room cleaners in Las Vegas. Am J Ind Med 48:326-337.

Lee PT, Krause N. 2002. The impact of a worker health study on working conditions. J Public Health Policy 23(3):268-285.

Loomis D, Richardson DB, Elliott L. 2005. Poisson regression analysis of ungrouped data. Occup Environ Med 62:325-329.
McCurdy SA, Samuels SJ, Carroll DJ, Beaumont JJ, Morrin LA. 2003. Agricultural injury in California migrant Hispanic farm workers. Am $\mathrm{J}$ Ind Med 44(3):225-235.

McGwin G, Jr., Enochs R, Roseman JM. 2000. Increased risk of agricultural injury among African-American farm workers from Alabama and Mississippi. Am J Epidemiol 152(7):640-650.

Mergler D. 1995. Adjusting for gender differences in occupational health studies. In: Messing K, Neis B, Dumais L, editors. Invisible: Issues in women's occupational health/La santé des travailleuses. Charlottetown, P.E.I., Canada: Gynergy Books. p 236-251.

Messing K. 2004. Physical exposures in work commonly done by women. Can J Appl Physiol 29(5):639-656.

Messing K, Tissot F, Saurel-Cubizolles M, Kaminski M, Bourgine M. 1998. Sex as a variable can be a surrogate for some working conditions. J Occup Environ Med 40:250-260.

Messing K, Punnett L, Bond MA, Alexanderson K, Pyle JL, Stock SR, Wegman DH, Zahm S, Stock SR, de Grosbois S. 2003. Be the fairest of them all: Challenges and recommendations for the treatment of gender in occupational health research. Am J Ind Med 43:618-629.

Milburn PD, Barrett RS. 1999. Lumbosacral loads in bedmaking. Appl Ergon 30(3):263-273.

Murray LR. 2003. Sick and tired of being sick and tired: Scientific evidence, methods, and research implications for racial and ethnic disparities in occupational health. Am J Public Health 93:221-226.

National Institute for Occupational Safety and Health. 1996. National Occupational Research Agenda: Special Populations at Risk. Cincinnati, OH: DHHS (NIOSH) Publication No. 96-115.

National Institute for Occupational Safety and Health. 2002. The changing organization of work and the safety and health of working people. Cincinnati, OH: DHHS (NIOSH) Publication No. 2002116

Parker E. 1999. Job quality in the hospitality industry: Findings from the San Francisco housekeeping study. Report to the Rockefeller Foundation. University of Wisconsin-Madison and University of California-Berkeley: Madison, Wisconsin, and Berkeley, California. p 23.

Pransky G, Benjamin K, Hill-Fotouhi C, Fletcher KE, Himmelstein J, Karz J. 2000. Work-related outcomes in occupational low back pain: A multidimensional analysis. Am J Ind Med 37(4):400-409.

Punnett L, Herbert R. 2000. Work-related musculoskeletal disorders: Is there a gender differential, and if so, what does it mean? In: Goldman MB, Hatch MC, editors. Women and health. San Diego, CA: Academic Press. p 474-492.

Research Randomizer. Social Psychology Network. Copyright (C) 1997-2008 by Geoffrey C. Urbaniak and Scott Plous. http:// www.randomizer.org/form.htm. Accessed April 10, 2007.

Richardson S, Ruser J, Suarez P. 2003. Hispanic workers in the United States: An analysis of employment distributions, fatal occupational injuries, and non-fatal occupational injuries and illnesses in Safety is Seguridad. National Research Council of the National Academies, Washington, DC

Robinson JC. 1989. Exposure to occupational hazards among Hispanics, blacks and non-Hispanic whites in California. Am J Public Health 79(5):629-630

Satcher D, Higginbotham EJ. 2008. The public health approach to eliminating disparities in health. Am J Public Health 98(9 Suppl): S8-S11.

Scherzer T, Rugulies R, Krause N. 2005. Work-related pain, injury, and barriers to workers' compensation among Las Vegas hotel room cleaners. Am J Public Health 95(3):478-488. 
Seifert AM, Messing K. 2006. Cleaning up after globalization: An ergonomic analysis of work activity of hotel cleaners. Antipode 38:557-578.

Simpson CL, Severson RK. 2000. Risk of injury in African American hospital workers. J Occup Environ Med 42(10):1035-1040.

Sogaard K, Fallentin N, Nielsen J. 1996. Work load during floor cleaning. The effect of cleaning methods and work technique. Eur J Appl Physiol Occup Physiol 73(1-2):73-81.

Stellman JM. 1999. Women workers: The social construction of a special population. Occup Med 14(3):559-580.
Treaster DE, Burr D. 2004. Gender differences in prevalence of upper extremity musculoskeletal disorders. Ergonomics 47(5):495526.

Wial H, Rickert J. 2002. U.S. Hotels and their workers: Room for improvement, in the state of U.S. Industries. AFL-CIO Working for America Institute.

Woods V, Buckle P, Haisman M. 1999. Musculoskeletal Health of Cleaners. Robens Centre for Health Ergonomics, European Institute for Health and Medical Sciences, University of Surrey, England: $\mathrm{p} 1-12$. 